The Effect of First-Hand and Second-Hand Knowledge on Perceived Group Homogeneity and Certainty about Stereotype-Based Inferences

Thalia H. Vrantsidis, William A. Cunningham University of Toronto

Preprint - Accepted in the journal Social Cognition

\title{
Author's note
}

Results from study 1 were published previously as part of the Proceedings of the 42nd Annual Conference of the Cognitive Science Society.

Supplementary materials are available online at https://osf.io/kv7er/.

Thank you to Jenny Hui, Subha Mustufa, and Neda Safaee-Rad for help with stimulus design and literature review. In addition, thanks to Neda Safaee-Rad, Hyuna (Hannah) Cho and Thaddea Chua for feedback on previous versions of these studies and help with data collection. Thanks to John Matelski for advice on statistical analyses. Thanks to the Social Cognitive Science lab, especially to Suraiya Allidina, Victoria Davis, Nathan Wheeler, Marius Golubickis, 
Alexandra Waddell, and Elizabeth Long for feedback on previous versions of this article. This research was funded by SSHRC.

Correspondence concerning this article should be addressed to Thalia H. Vrantsidis, Department of Psychology, University of Toronto, 100 Saint George Street, Toronto, ON, Canada, M5S 3G3. Contact: thalia.vrantsidis@mail.utoronto.ca; Phone: (416) 978-6903; Fax: (416) 978-4811 


\begin{abstract}
Stereotypes are often used to make inferences about others, yet can lead to problematic consequences, which get exacerbated when people are more confident in these inferences. The current research examines whether biases in people's first-hand and second-hand information about groups make groups appear overly homogeneous, leading to more confident inferences about group members. Supporting this, across two studies, groups appeared more homogeneous when people lacked first-hand information from personal experience with a group, and when stereotypes were based on second-hand information from the media or other people. However, only second-hand information increased confidence about group members, as lacking first-hand information reduced confidence about what groups and group members were like. Biases in homogeneity also had greater impact for typical rather than atypical group members. Thus, people may be especially confident in stereotype-based inferences when stereotypes are based on second-hand information, and when group members appear typical of their group.

Keywords: Stereotyping, Homogeneity, Certainty
\end{abstract}


The Effect of First-Hand and Second-Hand Knowledge on Perceived Group Homogeneity and Certainty about Stereotype-Based Inferences

People have an amazing ability to pick up on regularities in the world, and can often form beliefs and make inferences based on these regularities in ways that are in line with statistical principles. This applies in general (Griffiths et al., 2008) and can also apply when people form beliefs (or 'stereotypes', Ashmore \& Del Boca, 1981) about social groups (Jussim, 2017). For example, people might learn from experience how tall men and women are on average, and how much variability there is in each group's height. In this case, people can likely form unbiased beliefs about these properties - that is, people's beliefs will not tend to systematically deviate from the truth. This is in part because people tend to have large amounts of good-quality information about men and women's heights - most people have met a lot of men and women, and it is fairly easy to tell how tall someone is just by looking at them. More specifically, this information is likely unbiased, so that the distribution of heights that people know about (the 'sample distribution'), does not systematically differ from the true distribution of each gender's heights (the 'population distribution').

However, in many cases, people form beliefs about groups based on biased information that systematically misrepresents the group. For example, most people have not met many transgender people, or, depending where someone lives, they might not meet many people from other countries. In these cases, people may lack information about these groups, especially firsthand information learned from interacting with group members. The information people do have can then be biased, because their limited experience is less likely to reflect the full range of a group's variability (Konovalova \& Le Mens, 2020; Linville et al., 1989). People might also learn 
about groups through second-hand information, such as from the media or what other people say. People have various communication goals that can lead to systematic biases in the information received from others. In particular, people tend to selectively convey stereotype-consistent information to others (Kashima, 2000), which could lead second-hand information to similarly fail to reflect a group's full variability. Thus, both a lack of first-hand information and the presence of second-hand information about a group can lead to biases that portray groups as less variable (more homogeneous) ${ }^{1}$ than they actually are.

If these forms of biased information lead people to perceive groups as overly homogeneous, this could in turn increase people's confidence when using stereotypes to make inferences about group members. This increased confidence could increase the potential impact of these stereotypes, including their negative societal consequences. On the other hand, it is also possible that people's information could contain these biases without affecting their beliefs or inferences (Wegener et al., 1998; Whalen et al., 2018). If people in some sense realize that these information biases exist, they might be able to correct for them when forming beliefs about groups, so that groups are not perceived as overly homogeneous. Furthermore, even if people perceive a group as overly homogeneous, they will not necessarily be more confident when making stereotype-based inferences about group members. This could happen if other factors lead people to counteract any increased confidence (e.g. uncertainty about the stereotype itself), or if people simply do not apply the stereotype to particular group members (e.g. if group members are seen as atypical of their group; Wilson, 2016). Therefore, the main question this paper will address is if these two potential sources of information biases - the lack of first-hand information and the presence of second-hand information - make groups appear more 
homogeneous, and, in turn, if and when this makes people more confident when applying stereotypes to group members.

\section{Certainty in Stereotype-Based Inferences and Perceived Homogeneity}

Understanding when these types of information biases will affect confidence or certainty in people's stereotype-based inferences is important, because this certainty is a powerful determinant of how impactful these stereotypes will be. In particular, we focus here on people's certainty that someone will have a particular degree of an inferred characteristic - for example, someone might guess that a man they have never met will be $1.7 \mathrm{~m}$ tall (the average height of men), and they could be more or less certain that this man is exactly that height. When people are more certain about what a group member is like, this should amplify the effects of the stereotype, as people should be more likely to act based on their inferences, and less likely to consider other information that might go against the stereotype (Tormala, 2016). Especially when people have negative stereotypes about a group, greater confidence in stereotype-based inferences could therefore increase the chance of harming group members through prejudice or discrimination (Brauer \& Er-Rafiy, 2011).

People's confidence about what a group member is like depends on their beliefs about the group, and this can often occur in ways that suggest people are following principles of statistical inference. At least two different aspects of these beliefs about groups should matter here. The first is how homogeneous a group is thought to be (e.g. how similar men are in terms of their height). Several studies have found that when groups are seen as more homogeneous - that is, less variable on some characteristic - people are more certain about what members of that group are like (Figure 1a; Park \& Hastie, 1987; Ryan et al., 1996). This makes sense statistically, because, if the group really is more homogeneous, group members actually are more likely to be 
similar to the group average. A second aspect of people's beliefs that should matter is how certain people are about the group average (e.g. how certain someone is that the average height of men is $1.7 \mathrm{~m})$. When people are more certain about what a group is like on average, they should also be more certain that a particular group member will be similar to their estimate of the group average (Figure 1b). On the other hand, if someone has no idea what a group is like on average, they should have little confidence in inferring what that person is like solely based on their group membership. These two aspects of beliefs about groups are not fully independent. Instead, people tend to be more certain about the group average when a group is seen as more homogeneous (Figure 1c; Lambert et al., 1998, 2004). This also makes sense statistically, because if everyone in a group is the same, one can know for sure what the group is like on average even from just knowing about one person. This relationship means that seeing a group as more homogeneous can therefore increase certainty about group members through two paths: both directly, and indirectly through increasing certainty about the group average (Figure 1a-c).

\section{Sources of Bias in Perceived Homogeneity: Unfamiliarity or Lack of First-Hand}

\section{Knowledge}

Existing work suggests that people often use their beliefs about groups in statistically reasonable ways to determine their certainty about individual group members. However, these beliefs themselves could be biased, perhaps due to receiving biased information. In line with this, a lot of work has documented situations that can bias some groups to seem more homogeneous than others. For example, outgroups (Ostrom \& Sedikides, 1992), minority groups (Mullen \& Hu, 1989; Simon \& Mummendey, 1990), lower-status groups (Boldry et al., 2007), and unfamiliar groups (Linville et al., 1989) may all tend to be more seen as more homogeneous. We will focus here on unfamiliarity. Unfamiliarity can refer to lack of knowledge about a group from 
any source of information (first-hand or second-hand; Linville et al., 1989), though it has typically been operationalized as a lack of first-hand knowledge (e.g. Jones et al., 1981; Linville et al., 1996; Park et al., 1992, though see Bartsch et al., 1997). Unfamiliarity may be especially important because it could in part explain some of the other sources of biases in homogeneity just mentioned. This is because people may often be less familiar with outgroups, minority groups, and low-status groups, through having fewer chances to interact with them (Konovalova \& Le Mens, 2020; Linville et al., 1989), or less motivation to pay attention to or remember detailed information about them (Park \& Rothbart, 1982; Van Bavel \& Cunningham, 2012). Unfamiliarity has been proposed to affect perceived homogeneity in part because of biases in people's information, which can occur whenever only small amounts of information are available (Konovalova \& Le Mens, 2020; Linville et al., 1989). This is based on the statistical fact that sample variance tends to be smaller than population variance, and this is especially true for small sample sizes. This means that if someone has only met a few people in a group, they are especially unlikely to have met anyone who is an extreme outlier, simply because those outliers are less common. If people then use the variability of the known group members directly to estimate the variability of the group, people should tend to think the group is overly homogeneous, though this bias will get reduced as one meets more people. This implies that when people are less familiar with a group, the group may appear more homogeneous than when people are more familiar with it (Figure 1g). Some empirical research supports this claim, finding that unfamiliar groups are in fact seen as more homogeneous (Linville et al., 1989; Ryan et al., 2001; Ryan \& Bogart, 1997). However, other research found no significant relationship between familiarity and perceived homogeneity of a group (Guinote, 2001; Jones et al., 1981; Park et al., 1992; Ryan et al., 2001; Simon et al., 1991). These null results may indicate that 
people are correcting for biased information when estimating a group's homogeneity. (In statistics, this bias can be corrected for by using $\mathrm{N}-1$ rather than $\mathrm{N}$ in the denominator when estimating population variance from sample variance.) Alternatively, previous research may simply have lacked the power to reliably find these effects. Therefore, the present research will use highly powered studies to investigate whether or not unfamiliarity (in particular, a lack of first-hand knowledge) makes groups appear more homogeneous. Hypothesis 1a proposes that when people have less first-hand knowledge, they will think groups are more homogeneous, while the competing hypothesis $1 \mathrm{~b}$ proposes that first-hand knowledge will be unrelated to perceived homogeneity. Though these hypotheses could apply to when people lack either firsthand or second-hand knowledge, we focus on when people lack first-hand knowledge, because second-hand knowledge may contain additional biases that overwhelm these effects (discussed later).

The current research also examines two competing hypotheses about whether a lack of first-hand knowledge, assuming it does increase perceived homogeneity, will lead to greater confidence in stereotype-based inferences. One hypothesis (hypothesis $2 \mathrm{a}$ ) proposes that when people lack first-hand knowledge about a group, they will tend to be more confident making inferences about group members (due to thinking the group is more homogeneous). Though this has not been tested directly, previous theories have often assumed that this will occur. This can be seen, for example, when people argue for the importance of studying the causes of biases in homogeneity based on the consequences these biases can have, such as increased stereotyping, prejudice and discrimination (Linville et al., 1989; Ostrom \& Sedikides, 1992; Park et al., 1991). This assumes that causes of these biases, such as unfamiliarity, will in fact lead to their proposed consequences. 
However, even if unfamiliarity does increase perceived homogeneity, it is possible that people might be able to counteract its effects farther downstream, so that they are not more confident when making inferences about group members. The intuition here is that, if someone has not met many people from a particular group, such as people from Madagascar, they should take their small sample size into consideration and be less confident about what members of that group are like, not more confident. This can be accounted for in the current model if a lack of first-hand knowledge also makes people less certain about what the group is like on average (Figure 1e). This uncertainty about the group average could then counteract effects of seeing the group as overly homogeneous, so that, in total, a lack of first-hand knowledge may lead to little or no increase in certainty about group members. Thus, our alternative hypothesis $2 \mathrm{~b}$ proposes that when people lack first-hand knowledge about a group, people will be less certain (or not significantly more certain) about group members, due to being will be less certain about the group average. Existing research has not actually tested if this occurs, because it has only looked at either causes or consequences of perceived homogeneity (e.g. Park \& Hastie, 1987; Rubin \& Badea, 2012), rather than both of these effects simultaneously, along with potential counteracting factors (such as reduced certainty about the group average) that could be affected at the same time. Thus, even if the individual effects found in previous research hold (i.e. unfamiliarity increases perceived homogeneity, and perceived homogeneity increases certainty about group members), considering how all of these variables relate at the same time could provide a very different picture than studying them in isolation.

\section{Sources of Bias in Perceived Homogeneity: Second-Hand Knowledge}

Aside from personally interacting with group members, there are various other ways people can learn about groups, for example, through the media, or from what other people say. 
Though these sources of second-hand information might function similarly to first-hand information, they can also contain their own set of biases. One bias that second-hand knowledge may show is highlighted by research on stereotype communication. This research finds that, in serial reproduction tasks, where a story is retold and passed on through a chain of people, people tend to mostly pass on stereotype-consistent information (Kashima, 2000; Kashima et al., 2013; Zhao et al., 2016; but see e.g. Simpson \& Kashima, 2013). This can serve various communication goals, such as finding common ground (Klein et al., 2010), or informing others about stereotypes (Lyons \& Kashima, 2003). This tendency to pass on stereotype-consistent information suggests that second-hand information may be biased to not reflect the full variability of a group. If people are not aware of the biases in their second-hand information, this could mean that having more second-hand information about a group will make people think the group is more homogeneous (hypothesis 3a; Figure 1f; similar claims have been proposed previously: Linville \& Fischer, 1993; Park \& Hastie, 1987). However, if people recognize the biases in their information, they may be able to correct for them, so that second-hand knowledge has no effect on perceived homogeneity (hypothesis $3 b) .^{2}$ The present research tests which of these possibilities occurs.

If more second-hand knowledge leads to thinking that groups are more homogeneous, then this in turn should make people more certain about what members of those groups are like (hypothesis 4). In this case, these effects on certainty about group members are unlikely to be counteracted by other factors such as uncertainty about the group average. This is because when a stereotype is based on larger amounts of information (even if it is potentially biased secondhand information) people should be more confident that they know what the group is like on average (Figure 1f). This implies that second-hand knowledge should increase certainty about 
group members in two ways: through making groups appear overly homogeneous, and making people more certain about the group average. These effects cannot counteract each other, since both of these effects work in the same direction to increase certainty about group members.

\section{The moderating role of group members' typicality}

When people see groups as overly homogeneous, the impact of this bias on inferences about group members should also depend on how strongly the stereotype is applied to that group member. One important determinant of this is how typical the group member is thought to be of their group, with stereotypes being applied more strongly to more typical group members (Blair et al., 2004; Chasteen, 2000; Craig \& Bodenhausen, 2018; Fiske \& Neuberg, 1990; Wilson, 2016). One consequence of this discussed in previous research is that, for more typical group members, beliefs about a group's average traits will generally have more impact on inferences about the group member's traits. For example, a Chinese person who is good at math (therefore seen as typical of Chinese people, based on cultural stereotypes) is more likely to be judged as holding other stereotypically Chinese traits, compared to a Chinese person who is bad at math and seen as more atypical (Craig \& Bodenhausen, 2018). By analogy, we propose that typicality should also have other consequences. We propose that typicality will also affect how strongly beliefs about a group's homogeneity will impact people's certainty about the traits of group members. Thus hypothesis 5 proposes that perceived homogeneity should increase certainty about typical group members more strongly for than about atypical group members (Figure $1 \mathrm{~h}$ ). ${ }^{3}$ This highlights another case where biases in perceived homogeneity should be less impactful or problematic: when group members are seen as atypical of their groups. However, it also implies that these biases will be especially impactful on people who seem more typical of their groups. In many cases, this appearance of typicality is outside of people's control, yet can lead these 
individuals to experience the brunt of stereotyping and its negative consequences (e.g. harsher criminal sentencing of people with more prototypically Afrocentric facial features; Blair et al., 2004).

\section{Current research}

In two studies, the current research will test these hypotheses by examining the proposed path model (Figure 1). Both studies will examine whether or not two potential sources of biased information - a lack of first-hand knowledge, or the presence of second-hand knowledge - make groups seem more homogeneous, and make people more certain when applying stereotypes to group members (hypotheses 1-4). Study 2 will also examine the potential moderating role of typicality (hypothesis 5). Though the current studies use cross-sectional observational data, and therefore cannot test the causal direction of these effects, the results can provide evidence for whether or not the correlational relationships implied by the proposed causal processes exist.

\section{Figure 1}

Hypothesized path model

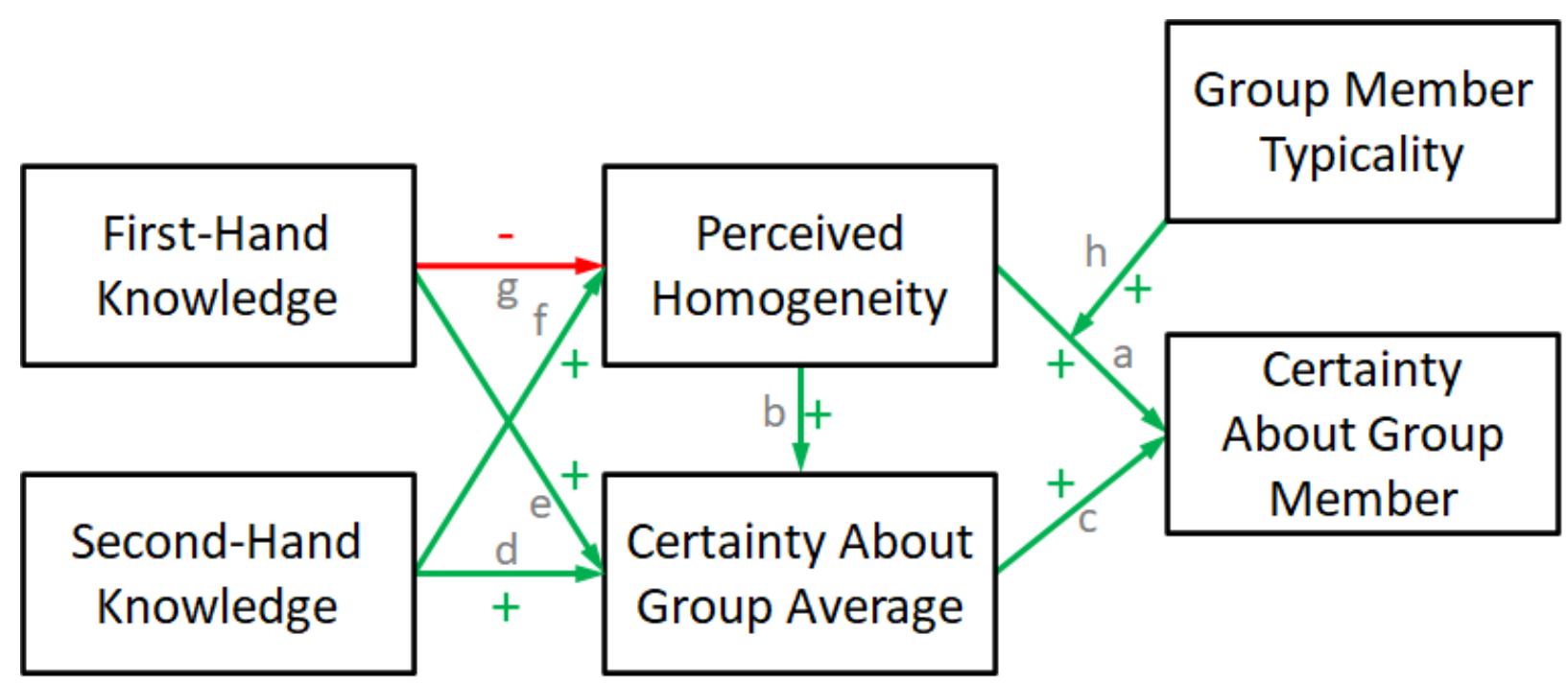




\section{Online Materials and Preregistrations}

The full experimental materials, raw data, analysis scripts, and preregistrations are available online on the Open Science Framework (https://osf.io/kv7er/). For study 1, study 2b and 2c, hypotheses, sample size, exclusion criteria, and the primary analysis were planned, and, for study $2 \mathrm{~b}$ and $2 \mathrm{c}$, preregistered, in advance of data collection. ${ }^{4}$ Study 1 was intended to be preregistered before data collection, however, due to an error and it was uploaded and registered at a later time. ${ }^{5}$ Any deviations from these plans/preregistrations, and any additional exploratory tests, have been noted.

\section{Study 1}

The proposed relationships were tested by investigating people's perceptions of various social groups that differed widely in the amount and type of knowledge participants were likely to have about them. For each group, participants made explicit ratings of each of the variables included in the main path model (Figure 1). Several aspects of this study ensured that it was well powered to find the effects of interest, especially considering the inconsistent results of previous research on unfamiliarity and perceived homogeneity. These included using a fairly large sample size, having each participant rate multiple social groups (at least 24), and using a range of groups to ensure enough variability in both types of knowledge - unlike previous work which primarily used one or two groups per study (e.g. Park et al., 1992; Ryan et al., 2001), and at times reported a lack of range in people's familiarity (Guinote, 2001).

\section{Methods}

Exact question wording for this study is listed in the supplementary online materials, and the list of social groups used in the study is available on OSF. 


\section{Participants}

103 participants (64 female, 36 male, 3 unspecified) from the University of Toronto's Rotman School of Management participant pool participated for course credit. Three participants were excluded: two did not complete the experiment due to time constraints, one because the program crashed. Sample size was decided a priori of at least 100 participants with usable data. Based on pilot data, this led to greater than $99 \%$ power to detect most effects, including all effects involving first-hand knowledge or perceived homogeneity (see supplementary online materials for details).

\section{Social Groups}

Participants completed a computerized survey where they answered questions about various social groups. 24 groups were selected to vary somewhat independently over a range of first-hand and second-hand knowledge. These groups were intended to fall into three conditions: high on both first-hand and second-hand knowledge (e.g. high school teachers), low on both types of knowledge (e.g. people from Madagascar), or high on second-hand but low on first-hand knowledge (e.g. politicians). Participants' knowledge ratings were used in analyses, so the accuracy of the intended condition assignment for each group was not essential. Groups in each knowledge condition were evenly split among different types of groups: careers, nationalities, subjects of university study, and hobbies. Participants also had the option to list their own nationality (if not included already) and up to 3 of their hobbies. These were used to attempt to find groups where participants would have more first-hand than second-hand knowledge.

\section{Certainty and Variability Ratings}

Participants answered several questions about the personality of members of each group in the study. A single randomly-assigned personality trait was used for all ratings that a participant 
made (extraversion, organization, adventurousness, or creativity). Participants rated the personality of a random member of each group, and their certainty that this was exactly what this person was like (measuring certainty about the group member). Participants then rated the average personality of the group as a whole, their certainty that this was the true average (measuring certainty about the group average), and how similar they thought members of this group were to each other on that personality trait (measuring perceived homogeneity). All questions were answered on continuous scales from 0 to 100 , first for the 24 pre-generated groups (groups randomly ordered). After this, participants could list their own groups, and then rate the personality of these groups.

\section{Knowledge Ratings}

Participants then reported how much knowledge they had about each group's personality. This was broken into three questions to measure different sources of knowledge: their amount of overall knowledge (i.e. based on any source of information), first-hand knowledge (i.e. based only on personal experience interacting with that group), and second-hand knowledge (i.e. based only on other sources of information, such as general knowledge, media, and what others have said about this group). This was asked for each group's personality in general, rather than for a specific trait. Each question was rated on a 7-point Likert scale $(1=$ None at all, $4=$ A moderate amount, $7=$ A great deal). The 24 pre-generated groups were rated in a randomized order, and any self-generated groups were rated after, in the order they had been listed.

\section{Additional Questions}

Participants answered how strongly they considered themselves to be part of each of the pre-generated nationality and hobby groups. Next, they selected any of the pre-generated groups 
that they did not understand the meaning of. Finally, they provided open-ended comments and filled out demographics questions.

\section{Analysis}

Minor deviations from analysis plans for study 1 are reported in the supplementary online materials. The conclusions reported here do not differ from those based on the original planned analyses, results of which are reported on the Open Science Framework.

\section{Data Preparation}

Responses to a particular social group were excluded for participants who reported that they did not understand what the group meant (3\% of data excluded). A participant's responses to a group were excluded if some questions used in the analyses were unanswered (an additional $2 \%$ of data was excluded here). ${ }^{6}$ The three knowledge ratings were rescaled to range from 0 to 100 to aid in the interpretability of model coefficients by putting them on the same scale as other ratings.

\section{Path Analysis}

All data were analyzed using multilevel modelling with the lmerTest package, v.3.1-0 (Kuznetsova et al., 2017) in R (R Core Team, 2018), with random intercepts included for each participant. ${ }^{7}$ As the predictions were not specific to within-person or between-person effects, these effects were not analyzed separately (Zigler \& Ye, 2019). The primary path model is specified in Figure 2. Specifically, this involved three regression models: 1) predicting certainty

about group members from perceived homogeneity, certainty about the group average, first-hand knowledge, and second-hand knowledge; 2) predicting perceived homogeneity from first-hand knowledge and second-hand knowledge; 3) predicting certainty about the group average from first-hand knowledge and second-hand knowledge. Mediation was tested by examining indirect 
effects along all paths connecting knowledge variables (first-hand and second-hand knowledge) to certainty about the group member. The direct effects of knowledge variables on certainty about the group member were included to test whether these effects were fully or partly mediated by perceived variability and certainty about the group average. Confidence intervals for fixed effects were computed based on Wald's tests. Indirect effects were assessed via computing the product of path coefficients, and total effects as the sum of these. Confidence intervals for these were computed using bootstrapping, using bias-corrected \& accelerated bootstrap intervals with stratified sampling based on participants as strata. Additional exploratory analyses are discussed later. Effect sizes for all results are reported as standardized regression coefficients (i.e. partial correlations). These can be interpreted in the same way as correlation coefficients, where 0.1 reflects a small effect, 0.3 a medium effect, and 0.5 a large effect (Cohen, 1992).

\section{Results}

The current study investigated how potential biases in the information people get about social groups influences people's certainty when inferring personality traits of members of those groups. Participants reported: their certainty when inferences about members of various social groups, two aspects of their beliefs about these social groups (perceived homogeneity of the group on that trait, and certainty about the group's average personality on that trait) and the amount of first-hand and second-hand knowledge they had about that group's personality. This study tests whether a lack of first-hand knowledge or the presence of second-hand knowledge makes groups seem more homogeneous, and whether this ultimately increases people's certainty about group members or gets counteracted through effects on certainty about the group average. 
Results are shown in Figure 2 and Table 1. Descriptive statistics are in Table 2.

Regression paths showed no signs of nonlinearity, and showed largely normally distributed residuals. $^{8}$

Figure 2

Study 1 path model results

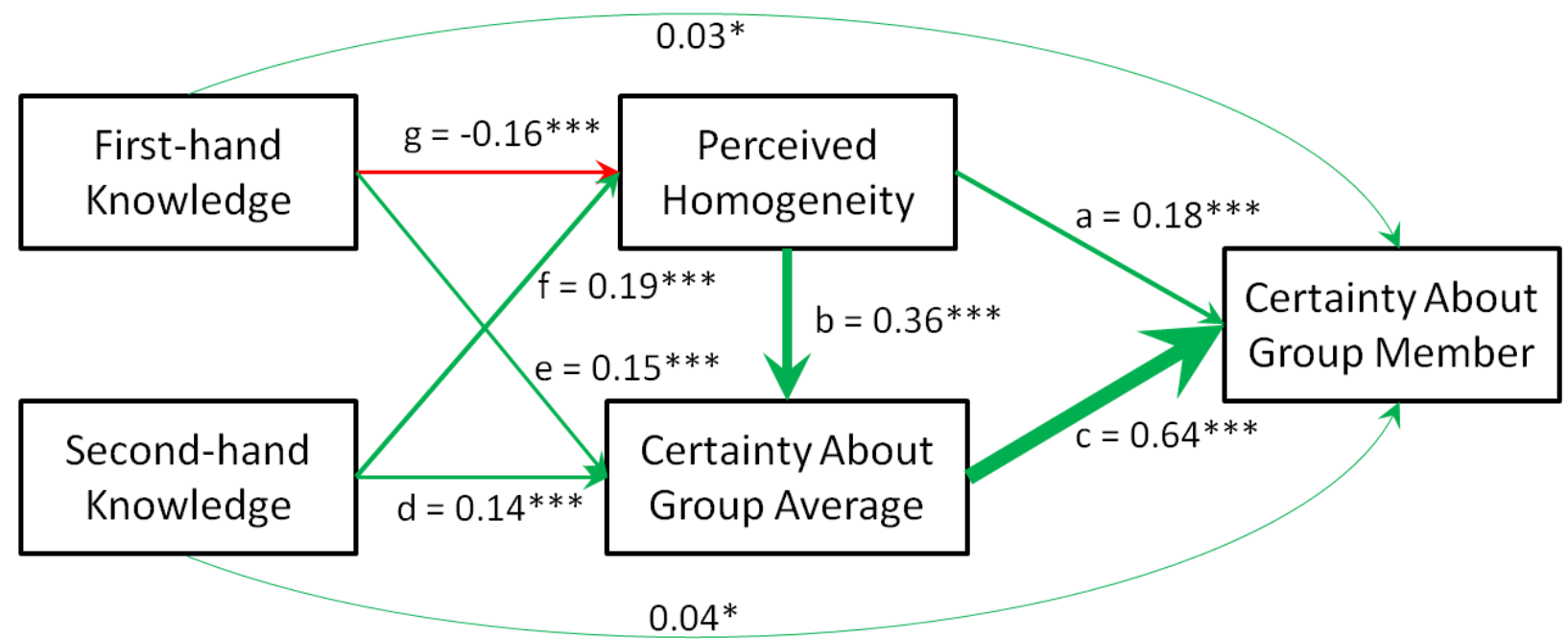

Note. Values shown are standardized regression coefficients, with significant paths marked as $* * *$ for $p<.001$ and $*$ for $p<0.5$. Line widths reflect effect sizes (standardized regression coefficients), green lines signify positive coefficients, and red lines signify negative coefficients.

Table 1

Study 1 total and indirect effects on certainty about group member

\begin{tabular}{lll}
\hline Effect & $b(95 \% \mathrm{CI})$ & $\beta$
\end{tabular}

Total effects of knowledge variables on certainty about group member

\begin{tabular}{lll}
\hline First-hand knowledge & $0.04(0.01,0.06)^{*}$ & 0.05
\end{tabular}


Second-hand knowledge

$0.14(0.11,0.18)^{*}$

0.17

\section{Indirect effects of knowledge variables on certainty about group member}

First-hand Knowledge $\rightarrow$ Perceived Homogeneity $\left(g^{*} a\right) \quad-0.02(-0.02,-0.01)^{*} \quad-0.02$

First-hand Knowledge $\rightarrow$ Perceived Homogeneity $\rightarrow$ Certainty $-0.02(-0.03,-0.01)^{*} \quad-0.03$

About Group Average $(\mathrm{g} * \mathrm{~b} * \mathrm{c})$

First-hand Knowledge $\rightarrow$ Certainty About Group Average $\quad 0.06(0.04,0.07)^{*} \quad 0.08$ $\left(\mathrm{e}^{*} \mathrm{c}\right)$

Second-hand Knowledge $\rightarrow$ Perceived Homogeneity (f*a) $\quad 0.02(0.02,0.03)^{*} \quad 0.03$

Second-hand Knowledge $\rightarrow$ Perceived Homogeneity $\rightarrow \quad 0.03(0.02,0.04)^{*} \quad 0.04$

Certainty About Group Average $(\mathrm{f} * \mathrm{~b} * \mathrm{c})$

Second-hand Knowledge $\rightarrow$ Certainty About Group Average $0.06(0.04,0.08)^{*} \quad 0.07$ $\left(\mathrm{d}^{*} \mathrm{c}\right)$

Note: $b$ is the unstandardized coefficients. $95 \%$ confidence intervals around this is reported.

Significant effects (confidence intervals not containing 0 ) are marked with a $* . \beta$ is the

standardized coefficient, which serves as a measure of effect size. Indirect effects labels (e.g.

$\left.\mathrm{g}^{*} \mathrm{a}\right)$ refer to the coefficients in Figure 2 which were multiplied to compute the indirect effect.

Table 2

Study 1 means, standard deviations, and correlations

\begin{tabular}{|c|c|c|c|c|c|c|c|}
\hline Variable & M & SD & 1 & 2 & 3 & 4 & 5 \\
\hline $\begin{array}{l}\text { 1. Certainty About Group } \\
\text { Member }\end{array}$ & 48.06 & 26.68 & & $.73 * * *$ & $.42 * * *$ & $.19 * * *$ & $.25^{* * *}$ \\
\hline $\begin{array}{l}\text { 2. Certainty About Group } \\
\text { Average }\end{array}$ & 49.29 & 27.00 & & & $.36 * * *$ & $.22 * * *$ & $.27 * * *$ \\
\hline 3. Perceived Homogeneity & 48.48 & 25.53 & & & & $-.04 *$ & $.09 * * *$ \\
\hline 4. First-hand Knowledge & 43.96 & 36.02 & & & & & $.61 * * *$ \\
\hline $\begin{array}{l}\text { 5. Second-hand } \\
\text { Knowledge }\end{array}$ & 48.58 & 31.41 & & & & & \\
\hline
\end{tabular}


Note. $*$ signifies $\mathrm{p}<.05, * *$ signifies $\mathrm{p}<.01, * * *$ signifies $\mathrm{p}<.001$. Correlations reflect multilevel correlations that account for repeated measures for each participant.

\section{Effects of Beliefs about a Group on Certainty about Group Members}

Before examining potential sources of biases in people's beliefs about groups, we examined whether these beliefs (specifically, the perceived homogeneity of a group, and one's certainty about the group average) affected confidence in people's stereotype-based inferences in the expected ways. As expected, people were more certain about a group member's traits when the group was perceived as more homogeneous (Figure 2a: $b=0.17,95 \%$ CI $[0.20,0.15], p$ $<.001, \beta=0.17$ ), and when people were more certain about the average level of the group's traits (Figure 2c: $b=0.65,95 \%$ CI $[0.62,0.68], p<.001, \beta=0.65$ ). Furthermore, when the group was seen as more homogeneous, people were more certain about the group average (Figure $2 \mathrm{~b}: b=$ $0.35,95 \% \mathrm{CI}[0.39,0.32], p<.001, \beta=0.33)$, supporting the idea that homogeneity can also increase certainty about group members indirectly, through increasing certainty about the group average. These results suggest that participants adjust their certainty about group members based on their beliefs about the group, in ways that are consistent with statistical principles.

\section{Effects of a Lack of First-Hand Knowledge}

These beliefs about groups - in particular, about a group's homogeneity - might in turn show biases based on the type and amount of information people have about the group. One potential source of bias in perceived homogeneity is due to a lack of first-hand knowledge. Consistent with previous theories of unfamiliarity (Linville et al., 1989), in this study, when people lacked first-hand knowledge about a group, they perceived the group to be more homogeneous (Figure 2g: $b=-0.10,95 \%$ CI $[-0.07,-0.13], p<.001, \beta=-0.14$ ). Supporting 
hypothesis 1a (but against hypothesis 1b), this provides evidence that biases due to lack of firsthand information can increase perceived homogeneity, and are not immediately corrected for.

This increased perceived homogeneity could lead to greater certainty when applying stereotypes to group members; however, it might also get counteracted if people are also less certain about what the group is like on average. In line with this second possibility, when people lacked first-hand knowledge, they were less certain about the group average (Figure $2 \mathrm{~d}: b=-$ $0.09,95 \%$ CI $[-0.06,-0.11], p<.001, \beta=-0.14)$. This should counteract the consequences of increased perceived homogeneity, so that a lack of first-hand knowledge might produce little or no increase in certainty about group members. In line with this, in total, when people had less first-hand knowledge about a group, they were not more certain about group members, and were in fact very slightly less certain (see Table 1). Therefore, in contrast to hypothesis $2 \mathrm{a}$ but in support of hypothesis $2 \mathrm{~b}$, lacking first-hand knowledge did not lead to greater confidence about group members, despite groups appearing more homogeneous.

\section{Effects of Second-Hand Knowledge}

Learning about groups through second-hand information could also potentially lead to biases that make groups seem more homogeneous, and make people more certain when applying stereotypes to members of those groups. To test this possibility, the effects of second-hand knowledge on perceived homogeneity were examined. As the work on stereotype communication suggests, when people had more second-hand knowledge, the group seemed more homogeneous (Figure 2f: $b=0.13,95 \%$ CI $[0.17,0.11], p<.001, \beta=0.17$ ). This supports hypothesis $3 \mathrm{a}$, and is consistent with the idea that widespread biases in the information people receive from others can make groups appear overly homogeneous, and that these biases are not immediately corrected for. 
These biases were further expected to have downstream effects, in terms of increased confidence about group members. This is because second-hand knowledge should also increase certainty about the group average, rather than decreasing it as in when people lack first-hand knowledge, so there is nothing to counteract the effects of biases in homogeneity. In line with this, when people had more second-hand knowledge about a group, they were more certain about the group average (Figure 2d: $b=0.10,95 \%$ CI [0.07, 0.13], $p<.001, \beta=0.14$ ). This should work together with the increased perceived homogeneity to make people more certain about what group members are like. Consistent with this, in total, people were more certain about group members when they had more second-hand knowledge about a group (see Table 1). These results support hypothesis 4: biases in second-hand knowledge can make groups seem more homogeneous, which can lead to greater certainty when stereotyping members of those groups.

\section{Mediation}

To provide further evidence that the proposed path model accounts for these effects, we examined if the effects of first-hand and second-hand knowledge on certainty about group members were mediated by the beliefs about the groups considered here: perceived homogeneity, and certainty about the group average. Consistent with these as mediators, all indirect effects were significant (see Table 1). Furthermore, these indirect effects almost fully mediated the relationship between both types of knowledge and certainty about group members. The remaining direct effects of both types of knowledge on certainty about group members had very small effect sizes, and only reached significance for second-hand knowledge (first-hand knowledge: $b=0.02,95 \%$ CI $[0.00,0.04], p=.05, \beta=0.02$; second-hand knowledge: $b=0.02$, $95 \%$ CI $[0.00,0.05], p=.03, \beta=0.03)$. This provides evidence that the proposed model accounts 
for nearly all of the relationship between first- and second-hand knowledge with certainty about group members.

\section{Exploratory Analyses}

Exploratory (non-planned) analyses supported the robustness of the results by ruling out two possible confounds. First, the present results were not accounted for by unmeasured differences between social groups, such as differences in their actual homogeneity, since the main results replicated when considering only variation within, rather than between, social groups (i.e. after subtracting each group's average from all variables; see supplementary online materials for results). Second, results were largely not accounted for or altered by participants' in/outgroup status. All results held after controlling for whether participants identified as part of the target group, and most results were not significantly altered by participants' identification with the group. The one exception is the effect of second-hand knowledge on perceived homogeneity: second-hand knowledge led to a smaller and non-significant increase in homogeneity when people did (vs. did not) identify as part of the group being judged. This might be due to people' tendency to seek out or receive different kinds of second-hand information about their ingroups, compared to their outgroups. For example, a Chinese person might be more likely to watch Chinese media, which may be less likely to portray Chinese people in overly homogeneous ways compared to other media sources. (Details of analyses and results are reported on OSF.)

\section{Discussion}

Study 1 found that both a lack of first-hand knowledge and the presence of second-hand knowledge were associated with perceiving groups as more homogenous. This supports the idea that both of these situations can lead to biases in the information people receive, and that these 
biases are not directly corrected for, thus making groups appear overly homogeneous (supporting hypothesis 1a and 3a). Yet, despite observing both of these effects on homogeneity, only secondhand knowledge was associated with greater certainty when applying stereotypes to members of those groups (supporting hypothesis 4), while lacking first-hand knowledge was associated with reduced certainty (supporting hypothesis $2 b$ ). This was because the downstream effects on people's certainty about group members also depended on people's certainty about what the group is like on average. The results suggested that second-hand knowledge makes people more certain about the group average, further increasing certainty about group members, while a lack of first-hand knowledge makes people less certain about the group average, counteracting any downstream increases in certainty about group members. These results imply that when stereotypes are learned through second-hand knowledge, such as from the media or other people, they are likely more impactful than when people simply lack first-hand knowledge of a group.

\section{Study 2}

Study 2 aimed to replicate the results of study 1 to ensure that they hold in a new sample and with a different study design. It also extended study 1 by exploring potential moderators of these results. In particular, this study focused on testing hypothesis 5: whether the perceived typicality of the group member moderates the effect of perceived homogeneity on certainty about group members.

Several changes to the study design were made to allow for testing whether the results replicate in a different task, and to make the methods more comparable to previous research.

The first change was to the description of the target group members. In study 1 people made inferences about a 'random person' from the group, where they could only use stereotypes to make their judgment. Study 2 aimed to ensure that the effects also held when people had 
something other than the stereotype to base their judgments on. Therefore, in study 2 , target group members were described using short scenarios involving ambiguous, trait-relevant behaviours, similar to those used in previous research (Ryan et al., 1996).

The second change was to the traits that were rated. Study 2 aimed to make sure all traits were stereotype-relevant. Therefore, rather than using the same trait for all groups as in study 1 (which was not necessarily stereotype-relevant for all groups), stereotypical and counterstereotypical traits were chosen for each group. A positive and negative trait of each type were also included, which differed from study 1 where all traits were positive. To make these changes, study 2 asked participants to make judgments about only 4 social groups, selected so that participants should have at least some basic knowledge or stereotypes about each group. This was done because if people did not have any stereotypes about a group (which may have occurred for some of the less familiar groups in study 1 - e.g. people from Madagascar), traits could not be stereotype-relevant.

Study 2 also included two additional measures of first-hand knowledge based on previous research (Park et al., 1992). This was done to ensure that the measure of first-hand knowledge in study 1 did not differ in some unexpected way from measures of familiarity used in previous research.

In addition to trying to replicate the results of study 1 with a new design, study 2 explored potential moderators of these results. In particular, study 2 examined the potential moderating role of the typicality of the target group member. Hypothesis 5 proposed that perceiving a group as more homogeneous should increase certainty about typical group members more strongly than about atypical group members, because the stereotype may be seen as less relevant or applicable to these atypical group members. The methods of study 2 allowed for examining typicality in 
two ways: through measuring participants' perceptions of how typical each target was of their group, and through manipulating whether the scenarios implied the person was more stereotypical or counterstereotypical of the group. In addition to testing hypothesis 5 , study 2 also explored whether either version of typicality, as well as the valence of the trait to be rated, might influence the results in any other way.

With these methods, three studies were collected (referred to as study $2 \mathrm{a}, 2 \mathrm{~b}$, and $2 \mathrm{c}$ ). Study $2 \mathrm{a}$ consisted of an exploratory study, while $2 \mathrm{~b}$ and $2 \mathrm{c}$ were preregistered replications. Hypotheses for the main path model, sample size, exclusion criteria and the analysis plan were preregistered; the same exclusion criteria and analysis methods were used in study $2 \mathrm{a}$. Aspects of the study that were not preregistered or deviated from the preregistration are noted below. In order to provide the most robust test of our hypotheses, results of a meta-analysis of all three studies are presented here. Results of each study individually are presented on OSF, and places where the results differed significantly across studies are noted. However, as the three studies were identical in both methods and participant population, we treat these differences as reflecting simply random noise or variability between participants, and focus mainly on the overall effects.

\section{Methods}

Exact wording for all questions and scenarios used in this study is provided on OSF.

\section{Participants}

All three studies were completed online through Amazon Mechanical Turk and the CloudResearch platform (Litman et al., 2017), using participants in the United States only. Study 2a included 115 participants (51 female, 64 male) of a total of 130 collected (i.e. people who both started the task and submitted it through Mechanical Turk). Study $2 \mathrm{~b}$ included 250 participants (105 female, 144 male, 1 other/prefer not to answer) of a total of 278 collected. 
Study 2c included 350 participants (167 female, 179 male, 2 other/prefer not to answer) of a total of 376 collected. (Exclusion criteria are listed under "Data Preparation".) Study 2a sample size was determined by deciding a priori that data collection would be stopped once 130 participants' data was collected (counting both included and excluded participants). In study $2 \mathrm{~b}$ and $2 \mathrm{c}$, data collection continued until the preregistered number of included participants specified above was reached. Study $2 \mathrm{~b}$ sample size was determined based on a power analysis using study 2 a results (see supplementary online materials). The sample size for study $2 \mathrm{c}$ was determined based on cost constraints.

\section{Social Groups and Target Rating Task}

As in study 1, participants completed a computerized survey where they answered questions about various social groups. Four social groups were used: African-Americans, Chinese-Americans, older adults, and marijuana users. For the target-rating task, participants read a scenario about 1 of 4 possible target individuals for each group, rated the target person's trait, and rated their certainty in this, using continuous scales from 0 to 100 . Traits consisted of a 2x2 design: either stereotypical or counterstereotypical, and either positive or negative. Scenarios involved short descriptions of a specific group member's behaviors, with each scenario corresponding to a specific trait. The following is an example scenario for a positive stereotypical trait (intelligent) for Chinese-Americans:

Meifeng was asked to meet her teacher after class one day. Much to her surprise, her teacher informed her that she had gotten the highest grade in the class on last weeks' math test. Meifeng was incredibly happy as she remembered studying hard for that test. 
In contrast, the following is an example scenario for a negative counterstereotypical trait (likely to break the law) for Chinese-Americans:

Meifeng was studying with her friends at school. When she went to the bathroom, she thought it would be funny to sketch a picture on the back of the stall door. She took a photo of it and later showed it to her friends, who all laughed.

As in these examples, the scenarios were designed to imply that the target might have the corresponding trait, but still be somewhat ambiguous about the extent to which the target had the trait, so that the stereotype could have some influence. Therefore, scenarios for the stereotypical traits should imply that the target is at least somewhat more typical of the group, compared to counterstereotypical scenarios, thus providing a manipulation of the target's typicality. The target person's group membership was conveyed as part of the scenario: through their name for African-American and Chinese-American targets, through mentioning their approximate age or status as a grandparent for older adult targets, and through describing marijuana use for marijuana users.

\section{Target Typicality and Group Ratings}

After rating the 4 targets, participants saw each of the previously seen scenarios and rated how typical the target person was of their group (e.g. African-Americans, etc.). Then, for each group, as in study 1, participants reported what they thought the group average was along the same trait that the target person was rated on previously, their certainty in this rating, and how similar they thought members of this group were to each other on that trait. All questions were answered on continuous scales from 0 to 100 .

\section{Knowledge Ratings}


Participants then reported how much knowledge they had about each group. Two new measures of first-hand knowledge were included based on previous work (Park et al., 1992), which asked how many group members they knew personally $(1=$ Don't know many, $7=$ Know a lot of them), and, on average, how well they knew them $(1=$ Don't know well, $7=$ Know very well). The other three knowledge measures from study 1 were also included, measuring overall knowledge, first-hand knowledge, and second-hand knowledge. These were altered to refer to knowledge about what each group was like (rather than about the group's personality) as some traits in study 2 were not strictly personality traits (e.g. physically fit). As in study 1 , none of these questions referenced specific traits.

\section{Additional Questions}

At the end of the knowledge rating section, two attention check questions were included that asked people to select a specific response on a Likert scale. In addition, in the knowledge rating section, the first measure of first-hand knowledge (which asked how many group members they know personally) was shown twice in a row. These four duplicate questions (one per group) were used as attention checks to ensure the consistency of participant's responses. Finally, participants filled out demographics questions and provided open ended comments.

\section{Data Preparation}

Across the three studies, ten participants were excluded as they did not finish the study. Participants were also excluded if they did not respond correctly to the two attention check questions which asked them to select a specific response, or if their responses to the four duplicate questions differed from their initial responses by a total absolute value of 5 or more across the 4 questions (excluding cases where they did not respond to the initial or duplicate question). This criterion allowed, for example, each answer to differ by 1 from the initial 
response. 69 participants were excluded based on all attention checks. ${ }^{9}$ If a participant completed the task more than once, only data from the first time was included (this exclusion criteria was not preregistered).

The three measures of first-hand knowledge were averaged together to form a single composite measure, as they were all highly correlated with each other (multilevel correlations accounting for repeated measures per participant ranged from $r=0.80$ to $r=0.81$, all $p<.001$ ).

The knowledge ratings were rescaled to range from 0 to 100 to aid in interpretability of model coefficients by putting them on the same scale as other ratings.

\section{Results}

The primary goal of study 2 was to test if the results of study 1 replicated in a new sample and with a different study design, which provided more information about target group members, used stereotype-relevant traits, and used additional measures of first-hand knowledge. For each study, the main path analyses were identical to those done in study 1. (Results of each study individually are reported on OSF). Though study $2 b$ and $2 c$ had preregistered the use of one-sided tests for certain paths, all tests are treated as two-sided to allow for the subsequent meta-analysis. Intra-class correlations for all three studies confirmed that social groups accounted for minimal clustering (all ICCs $<0.1$ ), therefore random intercepts based on social group were not required, while random intercepts for each participant allowed for accounting for the large participant-level clustering (see OSF for all ICCs). Regression paths for all studies showed no signs of nonlinearity and showed largely normally distributed residuals.

A fixed-effects meta-analysis was conducted based on the unstandardized and standardized regression coefficients for all paths in the path model and for all total and indirect effects, using the 'metafor' package, v. 2.1-0 (Viechtbauer, 2010) in R. Standard errors for each 
effect estimate were derived from the corresponding 95\% confidence intervals. Cochran's (1954)

Q statistic provides a test of heterogeneity of effect sizes, with a significant Q indicating that effects differed between one or more of the sub-studies involved. ${ }^{10}$

Results of the meta-analysis are summarized in Figure 4 and Table 3 and reported in detail below. Descriptive statistics are in Table 4. Additional analyses and results are described below.

\section{Figure 3}

Study 2 path model meta-analysis results

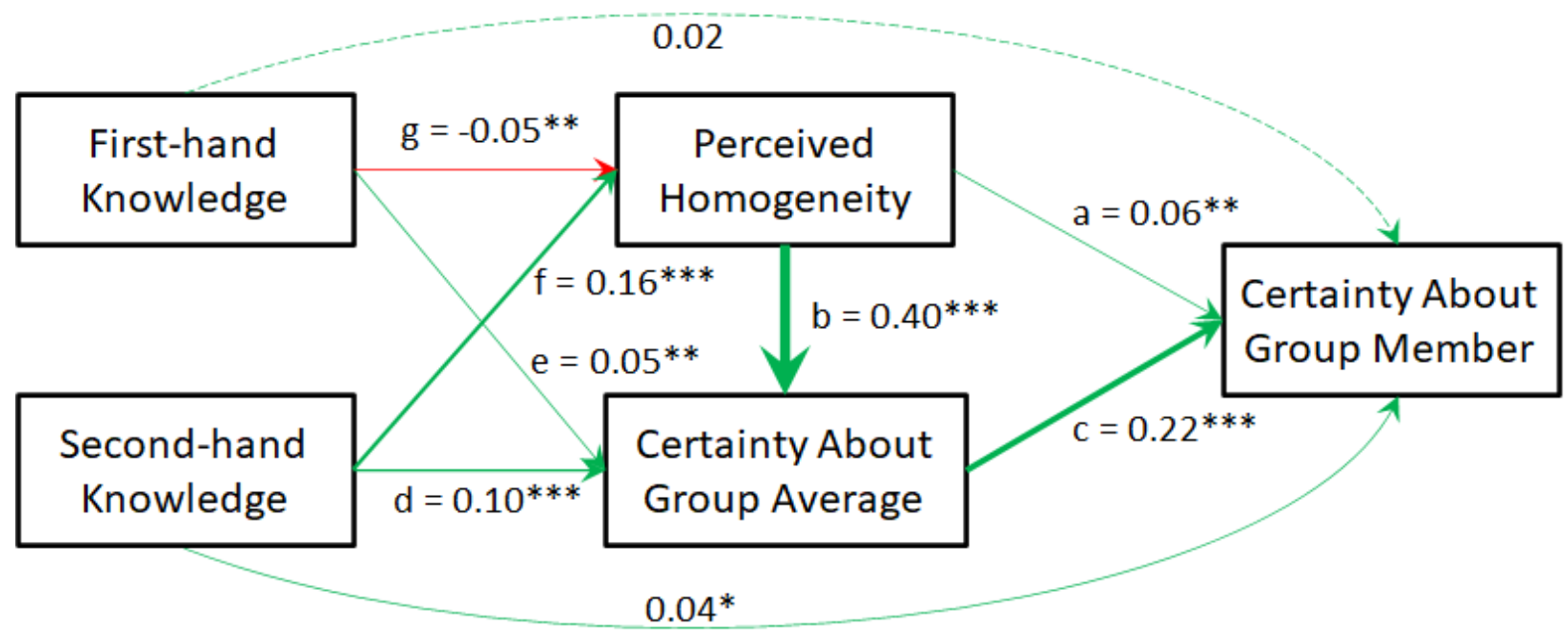

Note. Values shown are results from a meta-analysis of studies $2 \mathrm{a}-\mathrm{c}$, with values reflecting standardized regression coefficients, and significant paths marked as $* * *$ for $p<.001$, ** for $p<$ .01 and $*$ for $p<0.5$. Line widths reflect effect sizes (standardized regression coefficients), solid lines signify significant effects, dashed lines signify non-significant effects, green lines signify positive coefficients, and red lines signify negative coefficients.

\section{Table 3}


Study 2 total and indirect effects on certainty about group member

\begin{tabular}{llllll}
\hline Effect & $b(95 \% \mathrm{CI})$ & $\beta$ & $p_{b}$ & $\mathrm{Q}$ & $p_{Q}$ \\
\hline
\end{tabular}

Total effects of knowledge variables on certainty about group member

\begin{tabular}{llllll}
\hline First-hand knowledge & $0.02(0.00,0.09)$ & 0.10 & .06 & 3.11 & .21 \\
\hline Second-hand knowledge & $0.09(0.05,0.12)$ & 0.07 & $<.001^{* * *}$ & 0.22 & .90
\end{tabular}

\section{Indirect effects of knowledge variables on certainty about group member}

\begin{tabular}{llllll}
\hline $\begin{array}{l}\text { First-hand Knowledge } \rightarrow \text { Perceived } \\
\text { Homogeneity }(\mathrm{g} * \mathrm{a})\end{array}$ & $0.00(0.00,0.00)$ & -0.02 & .36 & 3.1 & .21 \\
\hline $\begin{array}{l}\text { First-hand Knowledge } \rightarrow \text { Perceived } \\
\begin{array}{l}\text { Homogeneity } \rightarrow \text { Certainty About Group } \\
\text { Average }\left(\mathrm{g}^{*} \mathrm{~b} \mathrm{c}\right)\end{array}\end{array}$ & $0.00(-0.01,0.00)$ & -0.01 & .08 & 1.88 & .39 \\
\hline $\begin{array}{l}\text { First-hand Knowledge } \rightarrow \text { Certainty } \\
\text { About Group Average }\left(\mathrm{e}^{*} \mathrm{c}\right)\end{array}$ & $0.01(0.00,0.01)$ & 0.01 & $.002^{* * *}$ & 0.03 & .98 \\
\hline $\begin{array}{l}\text { Second-hand Knowledge } \rightarrow \text { Perceived } \\
\text { Homogeneity (f*a) }\end{array}$ & $0.01(0.00,0.01)$ & 0.02 & $.007^{* *}$ & 0.62 & .74 \\
\hline $\begin{array}{l}\text { Second-hand Knowledge } \rightarrow \text { Perceived } \\
\text { Homogeneity } \rightarrow \text { Certainty About Group } \\
\text { Average (f*b*c) }\end{array}$ & $0.01(0.01,0.02)$ & 0.01 & $<.001^{* * *}$ & 2.16 & .34 \\
\hline $\begin{array}{l}\text { Second-hand Knowledge } \rightarrow \text { Certainty } \\
\text { About Group Average }\left(\mathrm{d}^{*} \mathrm{c}\right)\end{array}$ & $0.02(0.01,0.02)$ & 0.01 & $<.001^{* * * *}$ & 6.65 & $.04^{* 11}$ \\
\hline
\end{tabular}

Note. Results of a meta-analysis across studies $2 \mathrm{a}-2 \mathrm{c}$ are shown. $b$ is the unstandardized

coefficients. $95 \%$ confidence intervals around this is reported. $\beta$ is the standardized coefficient, which serves as a measure of effect size. $p_{b}$ is the p-value reflecting the significance of these effects. Q is Cochran's (1954) Q statistic which tests heterogeneity of effect sizes across studies 2a-c. The p-value for this test $\left(p_{Q}\right)$ indicates if effects vary significantly between the studies involved. $*$ signifies $\mathrm{p}<.06, * *$ signifies $\mathrm{p}<.01, * * *$ signifies $\mathrm{p}<.001$.

\section{Table 4}

Study 2 means, standard deviations, and correlations

\begin{tabular}{lllllllll}
\hline Variable & $\mathrm{M}$ & $\mathrm{SD}$ & 1 & 2 & 3 & 4 & 5 & 6
\end{tabular}


\begin{tabular}{lllllll}
\hline 1. Certainty About Group 67.59 & 24.19 & $.11 * * *$ & $.09 * * *$ & $.07 * *$ & $.07 * *$ & $.14 * * *$
\end{tabular} Member

2. Certainty About Group $64.2923 .49 \quad .37 * * * .13 * * * .16^{* * *} .13 * * *$
Average

\begin{tabular}{lllll}
\hline 3. Perceived Homogeneity 57.72 & 22.99 & 0.01 & $.06 * *$ & $.22 * * *$
\end{tabular}

\begin{tabular}{llll}
\hline 4. First-hand Knowledge & 49.48 & 29.59 & $.60 * * *$ \\
$.12 * * *$
\end{tabular}

\begin{tabular}{llll}
\hline 5. Second-hand & 54.14 & 25.02 & $.12 * * *$
\end{tabular}
Knowledge

6. Typicality $\quad 57.37 \quad 25.22$

Note. $* *$ signifies $\mathrm{p}<.01, * * *$ signifies $\mathrm{p}<.001$. Means, standard deviations and correlations are computed across all three studies. Correlations reflect multilevel correlations that account for repeated measures for each participant.

\section{Effects of Beliefs about a Group on Certainty about Group Members}

In study 1, certainty about the group member depended on people's beliefs about the group: specifically, the group's homogeneity, and certainty about the group average. Replicating study 1, perceived homogeneity was again associated with increased certainty about the group member (Figure 3a: $b=0.06,95 \%$ CI $[0.02,0.10], p=.002, \beta=0.06 ; \mathrm{Q}(\mathrm{df}=2)=0.77, p=.68$ ), and increased certainty in the group average (Figure $3 \mathrm{~b}: b=0.40,95 \%$ CI $[0.37,0.44], p<.001$, $\beta=0.40 ; \mathrm{Q}(\mathrm{df}=2)=0.25, p=.88)$. This in turn was associated with increased certainty about the group member (Figure 3c: $b=0.23,95 \%$ CI $[0.19,0.27], p<.001, \beta=0.22$ ). Though this last effect showed significant heterogeneity across studies $(\mathrm{Q}(\mathrm{df}=2)=7.30, p=.03)$ all studies had significant results in the same direction (Study 2a: $b=0.11,95 \% \mathrm{CI}[0.02,0.21], p=.02, \beta=$ 0.11; Study 2b: $b=0.23,95 \%$ CI $[0.16,0.30], p<.001, \beta=0.22$; Study $2 \mathrm{c}: b=0.27,95 \%$ CI $[0.21,0.32], p=<.001, \beta=0.27)$, indicating the effect was robust across studies. Thus, the relationship of beliefs about the group to certainty about group members held even when 
participants had other information about the group member to base their judgment on, beyond just the stereotype.

\section{Effects of a Lack of First-Hand Knowledge}

Next, effects of potential biases from lacking first-hand knowledge were examined. In study 1, a lack of first-hand knowledge was associated with groups appearing more homogeneous, suggesting that there are uncorrected biases in people's information when they have little experience with a group. This replicated in study 2: less first-hand knowledge was again associated with groups appearing more homogeneous (Figure $3 \mathrm{~g}: b=-0.04,95 \%$ CI $[-0.07$, -0.01], $p=.01, \beta=-0.05)$, though there was significant heterogeneity across studies $(\mathrm{Q}(\mathrm{df}=2)=$ 9.74, $p=.008$ ), with only study 2a having a significant effect (Study 2a: $b=-0.15,95 \%$ CI [$0.23,-0.07], p<.001, \beta=-0.20 ;$ Study $2 \mathrm{~b}: b=-0.04,95 \%$ CI $[-0.09,0.02], p=.18, \beta=-0.05$; Study 2c: $b=-0.01,95 \%$ CI $[-0.05,0.04], p=.78, \beta=-0.01)$. This may be due to instability in the estimates caused by the correlated nature of first-hand and second-hand knowledge, or variability between participants in the size of this biasing effect. Despite this variance, these results imply that, on average, a lack of first-hand knowledge makes groups appear more homogeneous, supporting hypothesis 1a. However, as in study 1, when people lacked first-hand knowledge about a group, they were also less certain about the group average (Figure 3e: $b=$ $0.04,95 \% \mathrm{CI}[0.02,0.07], p=.002, \beta=0.05 ; \mathrm{Q}(\mathrm{df}=2)=1.86, p=.39)$. This counteracted any tendency to be more certain about group members, so that, in total, people were instead slightly, though not quite significantly, less certain about group members (see Table 3). Thus, study 2 provided further support for hypothesis $2 \mathrm{~b}$.

\section{Effects of Second-Hand Knowledge}


Biases present in second-hand information were also expected to affect beliefs about a group's homogeneity, and certainty about group members. In study 1, second-hand knowledge was associated with greater perceived homogeneity of a group, and greater certainty about the group average; these two effects both contributed to greater certainty about the group member. In the present data, second-hand knowledge was again associated with greater perceived homogeneity of the group (Figure 3f: $b=0.14,95 \% \mathrm{CI}[0.10,0.18], p<.001, \beta=0.16 ; \mathrm{Q}(\mathrm{df}=2)$ $=0.02, p=.99)$, suggesting that second-hand knowledge contained biases that portray groups in overly stereotype-consistent ways which were not corrected for, supporting hypothesis $3 \mathrm{a}$. Second-hand knowledge was also associated with greater certainty about the group average (Figure 3e: $b=0.09,97 \%$ CI $[0.06,0.12], p<.001, \beta=0.10 ; \mathrm{Q}(\mathrm{df}=2)=1.35, p=.51)$. The combination of these effects meant that in total, second-hand knowledge was associated with greater certainty about group members (see Table 3), further supporting hypothesis 4 . Thus, these results again suggest that second-hand knowledge can bias groups to appear overly homogeneous, and that this can make people more certain when applying stereotypes to group members.

\section{Mediation}

As in study 1 , the proposed path model was further tested by examining if effects of firsthand and second-hand knowledge on certainty about group members were mediated by perceived homogeneity and certainty about the group average. Supporting their role as mediators, several of the indirect effects were significant, including all indirect effects involving second-hand knowledge, as well as the indirect of first-hand knowledge through certainty about the group average (see Table 3). The two indirect effects of first-hand knowledge involving perceived homogeneity did not reach significance (though one was close to significant), which 
may be due to the overall small effect of first-hand knowledge on perceived homogeneity. Altogether, these indirect effects fully mediated effects of first-hand knowledge (direct effect: $b$ $=0.02,95 \%$ CI $[-0.01,0.05], p=.18, \beta=0.02 ; \mathrm{Q}(\mathrm{df}=2)=3.61, p=.17)$, and almost fully mediated effects of second-hand knowledge, with a small direct effect that was not accounted for by the proposed mediators, where second-hand knowledge further increased certainty about group members (direct effect: $b=0.04,95 \%$ CI $[0.00,0.08], p=.03, \beta=0.04 ; \mathrm{Q}(\mathrm{df}=2)=0.03$, $p=.99)$. This suggests that the proposed model accounts for all of the relationship between firsthand knowledge and certainty about group members, and most of the relationship between second-hand knowledge and certainty about group members.

\section{Exploratory Analyses}

The main exploratory analyses concerned the moderating role of typicality. Though examining the role of typicality was a key a priori (preregistered) goal of study 2 , it is considered an exploratory analysis. This is because the specific hypotheses about effects of typicality were not preregistered, and the specific analyses to examine this were either preregistered as exploratory tests, or not preregistered at all. Other exploratory tests reported here similarly did not have preregistered hypotheses or analyses, or else were preregistered as exploratory analyses. A brief summary of the main results is presented here. Full details of all exploratory analyses and results are reported on OSF.

Typicality. The main exploratory analyses examined hypothesis 5: whether homogeneity would lead to greater increases in certainty about typical group members compared to atypical group members. Hypothesis 5 was supported when using both participant ratings of typicality, and manipulations of whether the target person was described with a stereotypical or counterstereotypical scenario (see Figure 4). In both cases, these variables interacted 
significantly with perceived homogeneity (perceived typicality: $b=0.00,95 \%$ CI $[0.00,0.00], p$ $=.03, \beta=0.03 ; \mathrm{Q}(\mathrm{df}=2)=0.20, p=.90 ;$ stereotypicality of scenario: $b=0.07,95 \% \mathrm{CI}[0.04$, $0.10], p<.001, \beta=0.03 ; \mathrm{Q}(\mathrm{df}=2)=0.22, p=.90)$. Homogeneity led to a greater increase in certainty about group members when those group members were rated as typical $(b=0.08,95 \%$ CI $[0.03,0.12], p=.002, \beta=0.07 ; \mathrm{Q}(\mathrm{df}=2)=0.56, p=.75)$ or described with stereotypical scenarios $(b=0.12,95 \% \mathrm{CI}[0.08,0.17], p<.001, \beta=0.12 ; \mathrm{Q}(\mathrm{df}=2)=0.29, p=.86)$, and a non-significant effect when group members were rated as atypical $(b=0.01,95 \%$ CI $[-0.08$, $0.11], p=.77, \beta=0.01 ; \mathrm{Q}(\mathrm{df}=2)=0.38, p=.83)$, or described with counterstereotypical scenarios $(b=-0.02,95 \%$ CI $[-0.07,0.03], p=.40, \beta=-0.01 ; \mathrm{Q}(\mathrm{df}=2)=0.94, p=.63)$. (Note that when including certainty about the group average in the model, the interaction with perceived typicality did not quite reach significance $(p=0.10)$, likely due to the high correlation of certainty about the group average and perceived homogeneity.) Thus the typicality of the group member is an important moderator of whether the perceived homogeneity of a group will affect certainty about group members.

\section{Figure 4}

Effect of perceived homogeneity on certainty about group members as a function of target typicality (left: perceived typicality; right: scenario stereotypicality)

Note. Confidence bands represent $95 \%$ confidence intervals. Plots are based on combined data from study 2a-c. All continuous variables are standardized. 
Other Exploratory Analyses. Additional exploratory analyses were performed to test if any of the effects in the main path model, aside from those examined above, depended on the perceived typicality of the group member, or the specific type of trait and scenario used (stereotypical or counterstereotypical, positive or negative). Only two significant interactions were found, though these were not of substantive interest. ${ }^{12}$ The lack of other interactions supports that, other than the effects of typicality reported above, the main results largely generalize across different degrees of target typicality, and for both positive and negative, and both stereotypical and counterstereotypical, traits and scenarios.

Additional analyses further supported the robustness of the results of the main path model. The main results all replicated when only considering responses from participants who were not part of the group being judged (i.e. were outgroup members), which ensured that results were not driven by differences in how ingroups and outgroups were perceived. The main results also largely replicated when considering only variations in people's perceptions of a particular social group (i.e. when subtracting the average for each group from all variables), ${ }^{13}$ which ensured the results were not driven by other differences between the particular social groups used, such as their actual degree of homogeneity.

\section{Discussion}

Study 2 replicated the results of study 1 with more a more realistic task where all traits were stereotype-relevant, and where other information about target individuals was available beyond just their group-membership. As in study 1, when people had less first-hand knowledge about a group, they thought the group was more homogeneous (supporting hypothesis 1a), yet were not more certain when applying stereotypes to group members, due to their uncertainty about what the group was like on average (supporting hypothesis $2 \mathrm{~b}$ ). Also as in study 1 , when 
people had more second-hand knowledge about a group, they thought the group was more homogeneous (supporting hypothesis 3a), and in this case did have greater confidence when applying stereotypes to group members (supporting hypothesis 4 ).

This study additionally examined the role of a group member's typicality in determining the impact of perceived homogeneity on specific group members. In support of hypothesis 5 , a group's perceived homogeneity increased certainty about typical group members, but had no significant effect for atypical group members. This suggests that biases in perceived homogeneity may be more consequential for group members who are seen as typical rather than atypical of their group, so that typical group members are more likely to be stereotyped overconfidently.

\section{General Discussion}

This paper investigated if potential biases in the information people have about social groups affect people's beliefs about those groups and inferences about group members, or if instead these biases can be corrected for or their influence counteracted. Specifically, this paper focused on whether two potential forms of biased information - due to lacking first-hand knowledge or having second-hand knowledge - could make groups appear more homogeneous, and if this in turn would lead to downstream increases in how certain people were when applying stereotypes to group members. It further examined if the impact of any biases in a group's perceived homogeneity depended on the typicality of the group member that the stereotype is applied to.

Across two studies, when people lacked first-hand knowledge about a group, the group appeared more homogeneous. This is in line with previous theories that highlight how small samples of experience will tend to under-represent the true variability of a group, a bias which 
people appear to have not corrected for when estimating the group's homogeneity, as suggested by Linville et al. (1989). However, despite this increased homogeneity, a lack of first-hand knowledge was not associated with greater certainty about group members. This is in part because when people lacked first-hand knowledge about a group, they counteracted any increased certainty about group members through their corresponding uncertainty about the group average, rendering any biases in perceived homogeneity less influential. On the other hand, second-hand knowledge about a group was associated with seeing groups as more homogeneous and being more confident when applying stereotypes to group members (as well as more confident about the group average). This suggests that the biases in second-hand information that portray groups in overly homogeneous (Kashima, 2000) exist broadly in everyday life, and these are not corrected for when estimating a group's homogeneity, nor are they counteracted in their impact on certainty about group members. Because of this, biases in second-hand information, such as from other people or the media, are likely to be much more impactful than biases due to lacking first-hand experience with a group. Study 2 additionally showed that the typicality of the group member was an important moderator of whether biased perceptions of a group's homogeneity would influence certainty about group members. Specifically, perceived homogeneity was primarily found to affect certainty about typical, not atypical, group members, thus identifying another case where the effects of biased information or beliefs about a group may be reduced.

Turning again to first-hand knowledge, despite inconsistencies in previous research, the current studies provide clear evidence supporting Linville et al.'s (1989) proposition that a lack of first-hand experience with a group can bias groups to appear more homogeneous. Two aspects of the current research likely enabled it to find these effects where some other studies did not 
(Guinote, 2001; Jones et al., 1981). First, the current studies were quite high-powered due to the use of both large sample sizes and within-subject designs. This is especially important because in study 2 the effect size for this relationship was quite small, making it likely that previous studies may have been underpowered to detect it reliably. Second, the current work accounted for both first-hand and second-hand knowledge simultaneously. As these were strongly correlated in the present research, yet showed opposite effects on perceived homogeneity, previous research could therefore have failed to find effects of first-hand knowledge because it did not control for the competing effects of second-hand knowledge. Therefore, despite the inconsistencies in previous research, the current results suggest that a lack of first-hand knowledge genuinely can alter perceptions of a group's homogeneity. However, in many cases, this lack of first-hand knowledge is likely to have little practical impact, in part due to its potentially small effect on perceived homogeneity.

Even if a lack of first-hand knowledge makes groups appear overly homogeneous, a further reason this bias may be of little impact is highlighted by the current research: when people do lack first-hand knowledge about a group, they can counteract any increased certainty about group members through their corresponding uncertainty about the group average. In other words, the same conditions that may lead to biases in perceived homogeneity also allow people to counteract its consequences, perhaps because they recognize that their stereotype is based on unreliable or biased information. The fact that the same situations that cause biases can also enable people to avoid their consequences is an important point, and could apply to many other biases. This shows the importance of not just identifying biases in isolation, but studying them within their broader context, simultaneously considering their causes, consequences, and potential counteracting factors that may be simultaneously affected. In contrast, most work on 
perceived homogeneity has focused on the causes of biased perceptions, without investigating their consequences (Boldry et al., 2007). Furthermore, the small amount of work looking at consequences of perceived homogeneity either did not consider its causes (e.g. Lambert et al., 2005; Ryan et al., 1996) or directly manipulated actual (Park \& Hastie, 1987) or perceived homogeneity (Brauer \& Er-Rafiy, 2011; Park \& Hastie, 1987), thus separating it from its naturally occurring causes. This could hide the fact that at least some of these causes may affect additional variables which may counteract any downstream effects on inferences, as observed here when a lack of first-hand knowledge also affected certainty about the group average. Future research can investigate whether other causes of biases in a group's perceived homogeneity (e.g., motivational factors; Pickett \& Brewer, 2001) are similarly counteracted.

While the current results imply that a lack of first-hand knowledge may be less problematic than previously thought, they also imply that second-hand knowledge about groups may be a much more problematic source of bias, one which has not been considered much in research on perceived homogeneity (though its role has been suggested previously; Linville \& Fischer, 1993; Park \& Hastie, 1987). The current results provide the first evidence that secondhand knowledge is associated with groups appearing more homogeneous, and with people having greater certainty when applying stereotypes to individual group members. This extends previous research based on serial reproduction tasks which showed that people tend to communicate primarily stereotype-consistent information (e.g. Kashima, 2000): the current work directly tests the consequences of this for perceived homogeneity and certainty about group members, and also shows that these biases are not constrained to serial reproduction tasks, but occur across the range of ways that people naturally learn from others, and across a range of realworld groups. 
Future research can continue to explore exactly when and why second-hand knowledge biases perceptions of homogeneity, and how this bias may be reduced. First, it will be important to understand which sources of second-hand knowledge contribute to this effect (e.g. other people vs. the media; news headlines vs. in-depth documentaries). Within each source, it will be important to identify the factors that promote or reduce the biases in the information people receive. As an example of this, people's tendency to pass on stereotype-consistent information has been found to depend on their context, beliefs, and goals, e.g. occurring less strongly when the stereotype is thought to be widely considered untrue (Lyons \& Kashima, 2003; see also Klein et al., 2010; Simpson \& Kashima, 2013). It might also be possible to make people aware of the biases in the information they receive from other people or media, which may allow them to correct for these biases when forming beliefs about groups and their homogeneity.

The current research also highlights the role of a group member's typicality in determining the consequences of biases in perceived homogeneity. In study 2 , perceived homogeneity was found to have more effect on certainty about group members when the group member was more typical, rather than atypical, of their group. This implies that any biases in perceived homogeneity should also have more effect on these group members. This result is consistent with previous research, which finds that stereotypes are applied more strongly to typical group members (Blair et al., 2004; Chasteen, 2000). While past work focused on how typicality affects inferences about group members' traits, the current work extended this to show it can affect people's certainty about those traits, by altering the impact of the perceived homogeneity of the group. This work highlights another way that people seen as more typical of their group may bear the brunt of the problematic aspects of stereotyping: these people are more likely to be stereotyped over-confidently when a group is seen as overly homogeneous. This 
might be one reason that African-Americans with more prototypical Afrocentric features are given harsher criminal sentences (Blair et al., 2004): if people have overly homogeneous stereotypes of African-Americans as dangerous (perhaps due to overly homogenous news and media portrayals), they may apply this stereotype overconfidently to prototypical-looking individuals. This overconfidence could then lead to downweighting or not seeking out other relevant evidence, evidence that might otherwise lead to milder sentencing. On the other hand, this work also highlights one way that the problems associated with biases in homogeneity might be reduced: by highlighting the unique and multifaceted nature of individual people, including the ways that they deviate from group stereotypes. However, this may not always be feasible: for example, a first impression of someone might give little indication of someone's unique or stereotype-inconsistent qualities.

People often learn about social groups in conditions of less-than-ideal information, such as when they lack first-hand experience with a group, or when they learn about a group through second-hand information sources. These conditions can lead to biases in the information people receive. The current results show that biases in people's information can lead to biases in how homogeneous groups are believed to be, and this in turn can make people more confident when applying stereotypes to individuals. However, these results also show that this may not always occur. This implies that we must study when biases in information or beliefs will have important consequences, or when they might be less impactful. This understanding this will allow those trying to address the negative societal consequences of stereotypes to focus on the cases most likely to cause problems. 


\section{Footnotes}

${ }^{1}$ We use homogeneity to refer to the variability or dispersion of a social group on some characteristic (Park \& Judd, 1990). However, in previous research, various other definitions have also been used (see Boldry et al., 2007; Linville et al., 1989). Two common ones are referring to the percent of a group thought to have a stereotypical trait (Park \& Judd, 1990) - which could actually be driven by seeing the group as having a different average or different variability on that trait - or referring to perceptual or memory confusions between group members (e.g. being unable to recognize if one has seen a particular group member or not; Boldry et al., 2007).

${ }^{2}$ Another reason this effect might not be observed is that unfamiliarity with a group, in terms of lacking second-hand information, could also bias groups to appear overly homogeneous. In line with this idea, people who have less factual knowledge about a country's history and politics have been found to perceive people from that country as more homogeneous (Bartsch et al., 1997). Depending on the relative size of these different possible biases, this could reduce or reverse any tendency for groups to seem more homogeneous when people have more secondhand knowledge about them.

${ }^{3}$ Though homogeneity may simply lead to a smaller or no increase in certainty about atypical compared to typical group members, it is also possible that homogeneity will decrease certainty in these cases. This is based on previous findings showing that stereotypes are applied least strongly to atypical members of homogeneous groups (Lambert et al., 2004). This could occur because, for homogeneous groups, atypical individuals may fall most noticeably outside the range of the groups' characteristics, so that the stereotype is seen as more noticeably irrelevant (Lambert, 1995; Lambert \& Wyer, 1990). Applied to the current work, this means that, for atypical group members, increasing homogeneity could make the stereotype more noticeably 
irrelevant to them, thus removing the stereotype as a relevant source of information about the person. This loss of information could therefore mean that people less certain in their judgements when groups are more, compared to less, homogeneous, because in the less-homogeneous case, the stereotype still provides some (though weak) information.

${ }^{4}$ The planned/preregistered hypotheses for study 1 and 2 involved individual paths in the path model, and did not include any effects of typicality. To more clearly convey the overall pattern of results that these paths produce, the various hypotheses were reformulated into hypotheses 1-4 as presented here, and specific predictions about the total effects of different types of knowledge were added (i.e. hypotheses $2 \mathrm{a}$ and $\mathrm{b}$, and $4 \mathrm{a}$ and $\mathrm{b}$ ). The goal to examine the moderating role of typicality was preregistered in study $2 \mathrm{~b}$ and $2 \mathrm{c}$ as an exploratory test, with no a priori predictions. Note that hypothesis 5 was generated based on previous research, therefore is independent of the current data, thus reducing the problems associated with hypothesizing after results are known (Rubin, 2017). Also note that in the preregistration documents for studies $2 \mathrm{~b}$ and $2 \mathrm{c}$, these studies are referred to as $2 \mathrm{a}$ and $2 \mathrm{~b}$, respectively.

${ }^{5}$ The intended preregistration was approved by the second author on Oct. 12, 2018, the blank preregistration was created Oct. 22, 2018, and data collection began Oct. 23, 2018.

${ }^{6}$ Results of the primary analysis largely replicated when all data for all participants who completed the experiment were included. That is, none of the results changed direction, all significant effects remained significant, and all non-significant effects remained non-significant, with the exception of the direct effect of first-hand knowledge on certainty about the group 
member, which became significant ( $p=.03$ instead of $p=.05$ with exclusions). This change does not alter main conclusions of the study.

${ }^{7}$ For study 1 , random intercepts were not included for the groups participants rated as there was minimal clustering based on group for all endogenous variables, with all ICCs $<0.1$ (homogeneity: $I C C=.03, p=.08$; certainty about group average: $I C C=.04, p=.03$; certainty about group member: $I C C=.04, p=.03)$. Note that for participant-generated groups, each of these was considered to be a unique cluster. On the other hand, random intercepts for each participant allowed for accounting for the large participant-level clustering (homogeneity: ICC $=.34, p<.001$; certainty about group average: $I C C=.47, p<.001$; certainty about group member: $I C C=.48, p<.001)$.

${ }^{8}$ For both study 1 and 2 , these assumptions were assessed through visual inspection of residual plots (vs. each predictor variable and as Q-Q plots). All plots are presented on OSF. Residuals for some of the regressions across the two studies showed minor deviations from normality; however, with the large sample sizes used in these studies, normality of residuals is not strictly required (Schmidt \& Finan, 2018).

${ }^{9}$ For study 2, results of the primary analysis largely replicated when data from all participants who completed the experiment was included (that is, when no one was excluded based on attention checks). The only differences involved changes in significance where pvalues shifted from just above to just below the significance threshold of 0.05 , or the reverse. Specifically, with all participants, the effect of first-hand knowledge on perceived homogeneity 
was not quite significant $(p=.06)$, and the total effect of first-hand knowledge on certainty about group members became significant $(p=.04)$.

${ }^{10}$ Fixed-effect (rather than random-effect) meta-analysis was used despite finding significant heterogeneity of the effects for some results. Fixed-effect modelling assumes there is a single true effect being estimated by each sub-study and that the variance in effect sizes is only due to sampling error, while random-effect modelling assumes that different effects are estimated by each sub-study due to differences in methods, population, etc. (Borenstein et al., 2011). Since all three sub-studies were completed within 1 month using the identical participantrecruitment and experimental methods, the fixed-effect approach was deemed more appropriate.

${ }^{11}$ Though the $\mathrm{d}^{*} \mathrm{c}$ indirect effect showed significant heterogeneity across studies, all studies had significant effects in the same direction (Study 2a: $b=0.01,95 \%$ CI $[0.00,0.02], \beta=$ 0.01; Study 2b: $b=0.02,95 \%$ CI [0.01, 0.04], $\beta=0.02$; Study 2c: $b=0.03,95 \%$ CI [0.02, 0.05], $\beta=0.03)$.

${ }^{12}$ One significant interaction showed that the effect of first-hand knowledge on homogeneity were significant for negative traits, but not positive traits. As study 1 found a significant effect using only positive traits, this result likely reflects a type 1 error, especially due to the large number of exploratory tests conducted. The other significant interaction showed that certainty about the group average had a smaller effect on certainty about the group member when those group members were described in counterstereotypical, rather than stereotypical scenarios. However, this interaction was only significant when perceived homogeneity was not included in the model. This suggests that the observed interaction may not reflect a unique effect, but may be 
driven simply by the correlation of certainty about the group average with perceived homogeneity.

${ }^{13}$ The only effect which did not quite reach significance was the effect of perceived homogeneity on certainty about the group member $(p=0.13)$. 


\section{References}

Ashmore, R. D., \& Del Boca, F. K. (1981). Conceptual approaches to stereotypes and stereotyping. Cognitive Processes in Stereotyping and Intergroup Behavior, 1, 35.

Bartsch, R. A., Judd, C. M., Louw, D. A., Park, B., \& Ryan, C. S. (1997). Cross-National Outgroup Homogeneity: United States and South African Stereotypes. South African Journal of Psychology, 27(3), 166-170. https://doi.org/10.1177/008124639702700306

Blair, I. V., Judd, C. M., \& Chapleau, K. M. (2004). The Influence of Afrocentric Facial Features in Criminal Sentencing. Psychological Science, 15(10), 674-679. https://doi.org/10.1111/j.0956-7976.2004.00739.x

Boldry, J. G., Gaertner, L., \& Quinn, J. (2007). Measuring the measures: A meta-analytic investigation of the measures of outgroup homogeneity. Group Processes \& Intergroup Relations, 10(2), 157-178.

Borenstein, M., Hedges, L. V., Higgins, J. P. T., \& Rothstein, H. R. (2011). Introduction to Meta-Analysis. John Wiley \& Sons.

Brauer, M., \& Er-Rafiy, A. (2011). Increasing perceived variability reduces prejudice and discrimination. Journal of Experimental Social Psychology, 47(5), 871-881.

Chasteen, A. L. (2000). The Role of Age and Age-Related Attitudes in Perceptions of Elderly Individuals. Basic and Applied Social Psychology, 22(3), 147-156. https://doi.org/10.1207/S15324834BASP2203_3

Cochran, W. G. (1954). The Combination of Estimates from Different Experiments. Biometrics, 10(1), 101-129. https://doi.org/10.2307/3001666

Cohen, J. (1992). A power primer. Psychological Bulletin, 112(1), 155. 
Craig, M. A., \& Bodenhausen, G. V. (2018). Category (Non)Fit Modulates Extrapolative Stereotyping of Multiply Categorizable Social Targets. Social Cognition, 36(5), 559-588. https://doi.org/10.1521/soco.2018.36.5.559

Fiske, S. T., \& Neuberg, S. L. (1990). A Continuum of Impression Formation, from CategoryBased to Individuating Processes: Influences of Information and Motivation on Attention and Interpretation. In M. P. Zanna (Ed.), Advances in Experimental Social Psychology (Vol. 23, pp. 1-74). Academic Press. https://doi.org/10.1016/S0065-2601(08)60317-2

Griffiths, T. L., Kemp, C., \& Tenenbaum, J. B. (2008). Bayesian models of cognition. In R. Sun (Ed.), The Cambridge handbook of computational cognitive modeling. Cambridge University Press.

Guinote, A. (2001). The perception of group variability in a non-minority and a minority context: When adaptation leads to out-group differentiation. British Journal of Social Psychology, $40(1), 117-132$.

Jones, E. E., Wood, G. C., \& Quattrone, G. A. (1981). Perceived variability of personal characteristics in in-groups and out-groups: The role of knowledge and evaluation. Personality and Social Psychology Bulletin, 7(3), 523-528.

Jussim, L. (2017). Précis of Social Perception and Social Reality: Why accuracy dominates bias and self-fulfilling prophecy. Behavioral and Brain Sciences, 40. https://doi.org/10.1017/S0140525X1500062X

Kashima, Y. (2000). Maintaining cultural stereotypes in the serial reproduction of narratives. Personality and Social Psychology Bulletin, 26(5), 594-604. 
Kashima, Y., Lyons, A., \& Clark, A. (2013). The maintenance of cultural stereotypes in the conversational retelling of narratives. Asian Journal of Social Psychology, 16(1), 60-70. https://doi.org/10.1111/ajsp.12004

Klein, O., Clark, A. E., \& Lyons, A. (2010). When The Social Becomes Personal: Exploring The Role Of Common Ground In Stereotype Communication. Social Cognition, 28(3), 329352.

Konovalova, E., \& Le Mens, G. (2020). An information sampling explanation for the in-group heterogeneity effect. Psychological Review, 127(1), 47.

Kuznetsova, A., Brockhoff, P. B., \& Christensen, R. H. B. (2017). lmerTest Package: Tests in Linear Mixed Effects Models. Journal of Statistical Software, 82(1), 1-26. https://doi.org/10.18637/jss.v082.i13

Lambert, A. J. (1995). Stereotypes and social judgment: The consequences of group variability. Journal of Personality and Social Psychology, 68(3), 388-403. https://doi.org/10.1037/0022-3514.68.3.388

Lambert, A. J., Barton, L. R., Lickel, B., \& Wells, J. (1998). The influence of group variability and processing goals on the ease of making judgments about social categories. Personality and Social Psychology Bulletin, 24(8), 807-820.

Lambert, A. J., Chasteen, A. L., Payne, B. K., \& Shaffer, L. (2004). Typicality and group variability as dual moderators of category-based inferences. Journal of Experimental Social Psychology, 40(6), 708-722.

Lambert, A. J., Payne, B. K., Ramsey, S., \& Shaffer, L. M. (2005). On the predictive validity of implicit attitude measures: The moderating effect of perceived group variability. Journal 
of Experimental Social Psychology, 41(2), 114-128.

https://doi.org/10.1016/j.jesp.2004.06.006

Lambert, A. J., \& Wyer, R. S. (1990). Stereotypes and social judgment: The effects of typicality and group heterogeneity. Journal of Personality and Social Psychology, 59(4), 676-691. https://doi.org/10.1037/0022-3514.59.4.676

Linville, P. W., \& Fischer, G. W. (1993). Exemplar and Abstraction Models of Perceived Group Variability and Stereotypicality. Social Cognition, 11(1), 92-125. https://doi.org/10.1521/soco.1993.11.1.92

Linville, P. W., Fischer, G. W., \& Salovey, P. (1989). Perceived distributions of the characteristics of in-group and out-group members: Empirical evidence and a computer simulation. Journal of Personality and Social Psychology, 57(2), 165.

Linville, P. W., Fischer, G. W., \& Yoon, C. (1996). Perceived covariation among the features of ingroup and outgroup members: The outgroup covariation effect. Journal of Personality and Social Psychology, 70(3), 421.

Litman, L., Robinson, J., \& Abberbock, T. (2017). TurkPrime.com: A versatile crowdsourcing data acquisition platform for the behavioral sciences. Behavior Research Methods, 49(2), 433-442. https://doi.org/10.3758/s13428-016-0727-z

Lyons, A., \& Kashima, Y. (2003). How Are Stereotypes Maintained through Communication? The Influence of Stereotype Sharedness. Journal of Personality and Social Psychology, 85(6), 989-1005.

Mullen, B., \& Hu, L. (1989). Perceptions of ingroup and outgroup variability: A meta-analytic integration. Basic and Applied Social Psychology, 10(3), 233-252. 
Ostrom, T. M., \& Sedikides, C. (1992). Out-group homogeneity effects in natural and minimal groups. Psychological Bulletin, 112(3), 536.

Park, B., \& Hastie, R. (1987). Perception of variability in category development: Instance-versus abstraction-based stereotypes. Journal of Personality and Social Psychology, 53(4), 621.

Park, B., \& Judd, C. M. (1990). Measures and models of perceived group variability. Journal of Personality and Social Psychology, 59(2), 173-191. https://doi.org/10.1037/00223514.59.2.173

Park, B., Judd, C. M., \& Ryan, C. S. (1991). Social categorization and the representation of variability information. European Review of Social Psychology, 2(1), 211-245.

Park, B., \& Rothbart, M. (1982). Perception of out-group homogeneity and levels of social categorization: Memory for the subordinate attributes of in-group and out-group members. Journal of Personality and Social Psychology, 42(6), 1051.

Park, B., Ryan, C. S., \& Judd, C. M. (1992). Role of meaningful subgroups in explaining differences in perceived variability for in-groups and out-groups. Journal of Personality and Social Psychology, 63(4), 553.

Pickett, C. L., \& Brewer, M. B. (2001). Assimilation and Differentiation Needs as Motivational Determinants of Perceived In-group and Out-Group Homogeneity. Journal of Experimental Social Psychology, 37(4), 341-348. https://doi.org/10.1006/jesp.2000.1469

R Core Team. (2018). R: A language and environment for statistical computing. R Foundation for Statistical Computing. https://www.R-project.org/

Rubin, M. (2017). When Does HARKing Hurt? Identifying When Different Types of Undisclosed Post Hoc Hypothesizing Harm Scientific Progress. Review of General Psychology, 21(4), 308-320. https://doi.org/10.1037/gpr0000128 
Rubin, M., \& Badea, C. (2012). They're all the same!... But for several different reasons: A review of the multicausal nature of perceived group variability. Current Directions in Psychological Science, 21(6), 367-372.

Ryan, C. S., \& Bogart, L. M. (1997). Development of new group members' in-group and outgroup stereotypes: Changes in perceived variability and ethnocentrism. Journal of Personality and Social Psychology, 73(4), 719.

Ryan, C. S., Judd, C. M., \& Park, B. (1996). Effects of racial stereotypes on judgments of individuals: The moderating role of perceived group variability. Journal of Experimental Social Psychology, 32(1), 71-103.

Ryan, C. S., Robinson, D. R., \& Hausmann, L. R. (2001). Stereotyping among providers and consumers of public mental health services: The role of perceived group variability. Behavior Modification, 25(3), 406-442.

Schmidt, A. F., \& Finan, C. (2018). Linear regression and the normality assumption. Journal of Clinical Epidemiology, 98, 146-151. https://doi.org/10.1016/j.jclinepi.2017.12.006

Simon, B., Glassner-Bayerl, B., \& Stratenwerth, I. (1991). Stereotyping and Self-Stereotyping in a Natural Intergroup Context: The Case of Heterosexual and Homosexual Men. Social Psychology Quarterly; Washington, 54(3), 252.

Simon, B., \& Mummendey, A. (1990). Perceptions of relative group size and group homogeneity: We are the majority and they are all the same. European Journal of Social Psychology, 20(4), 351-356.

Simpson, A., \& Kashima, Y. (2013). How can a stereotype inconsistency bias be encouraged in communication? Asian Journal of Social Psychology, 16(1), 71-78. https://doi.org/10.1111/ajsp.12010 
Tormala, Z. L. (2016). The role of certainty (and uncertainty) in attitudes and persuasion. Current Opinion in Psychology, 10, 6-11.

Van Bavel, J. J., \& Cunningham, W. A. (2012). A social identity approach to person memory: Group membership, collective identification, and social role shape attention and memory. Personality and Social Psychology Bulletin, 38(12), 1566-1578.

Viechtbauer, W. (2010). Conducting meta-analyses in R with the metafor package. Journal of Statistical Software, 36(3), 1-48. https://doi.org/10.18637/jss.v036.i03

Wegener, D., Petty, R., \& Dunn, M. (1998). The Metacognition of Bias Correction: Naive Theories of Bias and the Flexible Correction Model. In Metacognition: Cognitive and Social Dimensions (pp. 202-227). SAGE Publications Ltd. https://doi.org/10.4135/9781446279212

Whalen, A., Griffiths, T. L., \& Buchsbaum, D. (2018). Sensitivity to shared information in social learning. Cognitive Science, 42(1), 168-187.

Wilson, A. R. (2016). How African American Male Typicality Affects In-Group Stereotyping and Belonging: A Cross-Sectional Analysis [UC Santa Cruz]. https://escholarship.org/uc/item/1q84n6zx

Zhao, Y., Zhao, Y., \& Zhang, J. (2016). Transmitting Stereotype-Relevant Information in Conversation: Evidence from Chinese Undergraduates. Social Behavior and Personality; Palmerston North, 44(7), 1069-1078. http://dx.doi.org.myaccess.library.utoronto.ca/10.2224/sbp.2016.44.7.1069

Zigler, C. K., \& Ye, F. (2019). A Comparison of Multilevel Mediation Modeling Methods: Recommendations for Applied Researchers. Multivariate Behavioral Research, 54(3), 338-359. https://doi.org/10.1080/00273171.2018.1527676 
